\title{
Effe nog eens zeggen. De weggelaten klanken in het Nederlands - de afgebroken bruggen voor een Tsjech?
}

\section{Can You Repeat It? The Omitted Speech Sounds in Dutch - Broken Bridges for a Czech?}

\author{
Marta Kostelecká
}

\begin{abstract}
Czech and Dutch differ among others in terms of reduction processes. Spoken Dutch can sometimes be difficult to understand for a Czech. This is due to the fact that there is a lot of reduction in sounds. On the one hand, the reduction can be at the level of the dropped word ends or omitted vowels in unstressed syllables. This kind of reduction can still be identified in many cases by a speaker of Dutch as a foreign language. In addition, as Ernestus et. al. (2016) calls it, extreme reduction can occur where the words and sentences are reduced. In such cases, this phonological process causes requests in the perception of such utterances by speaker of Dutch as a foreign language. In this article I give a description of the results of a pilot study carried out among Czech students of Dutch at A2+ level that was focused on understanding reduced utterances. Moreover, I formulate an outline for further research.
\end{abstract}

\section{Keywords}

reduction, Dutch, Czech, Dutch as a Foreign Language, connected speech, vowels, consonants 


\section{Inleiding}

In mijn vorige bijdragen ${ }^{1}$ heb ik al meermaals gesproken over de bouwstenen die de pilaren van de grote brug ondersteunen die we de verstaanbare uitspraak van het Nederlands door een NVT-leerder kunnen noemen. De bouwstenen zijn de afzonderlijke klanken van het Nederlands en van het Tsjechisch en de correcte en verstaanbare realisatie ervan.

Ik heb ook meerdere keren geopteerd voor een grondigere aanpak van de uitspraaklessen aan Tsjechische studenten Nederlands omdat ik steeds het gevoel heb dat het werk aan de "variërende intonatie, juiste nadruk in de zinnen en het uitdrukken van fijnere betekenisnuances" zoals de fonologische competentie bij het niveau C1 in het ERK (ERK: 110) omschreven staat, ook op een andere manier kan of zelfs beter moet worden bereikt.

In deze bijdrage wil ik op een aantal punten reflecteren waarmee het uitspraakonderwijs in mijn opinie te kampen heeft en wil ik de vraag beantwoorden wat eigenlijk de bruggen in het uitspraakonderwijs zijn die we nog moeten weten te slaan.

In het uitspraakonderwijs hebben we als eerste de struikelblok van twee oevers. Aan de ene kant ligt fonetiek - de realiteit en aan de andere oever ligt fonologie - het systeem, het ideaal. En soms lijken die twee onoverbrugbaar - ten eerste voor de studenten om te begrijpen wat het vaarwater is van ieder van deze twee disciplines en ten tweede misschien zelfs voor de wetenschappers die zien dat er aan de ene kant een systeem is maar de eigenlijke realisatie ervan kan soms heel divers zijn, wat natuurlijk niet uitsluit dat de realisatie binnen de perken van het systeem blijft. Laten we denken aan de simpele zin Ik weet het niet, aan alle fonemen die er in deze zin normaal gesproken aanwezig zijn en aan de vele verschillende realisaties ervan waarbij we met minder dan de helft van de klanken kunnen eindigen - kweetetnie bijvoorbeeld.

Een ander voorbeeld van twee oevers die verdeeld zijn door een rivier is dan de gesproken taal zelf. Enerzijds hebben we het omstreden begrip van de "norm" - de vorm van de taal die de gemeenschap deelt en die de "culturele identiteit" van de taalgemeenschap vormt (Beheydt, 2010:121). Deze "norm" is dan ook opgenomen als voorbeeld in de leerboeken en uiteraard ook in de uitspraakleergangen. Aan de andere oever vindt men dan de gesproken taalvariëteit en soms is de brug tussen de norm en de alledaags gesproken variëteit figuurlijk soms afgebroken.

Er zijn dus twee oevers van de taalrivier, aan de ene kant ligt het ideaal en aan de andere kant de realiteit. Als NVT-leerder en als taaldocent hebben we de taak om bruggen te slaan zodat we met plezier naar de dynamische, soms wilde en soms eigenzinnige taalrivier kunnen kijken en van al haar complexiteit kunnen genieten.

Als taaldocent heb ik in de uitspraaklessen aan de eerstejaars - die al dichtbij het taalniveau A2 waren - een minitoets gegeven. In totaal had ik een groep van 17 studenten

1 Kostelecká, Marta. De struikelblokken van de uitspraak van het Nederlands bij Tsjechische studenten. Roczniky Humanystyczne. Lublin, 2016, jaargang 64, nr. 5, pp. 83-93. ISSN 0035-7707 of Kostelecká, Marta. Het Tsjechisch Nederlands in de oren van de Nederlandse en Vlaamse moedertaalsprekers. In AUC Philologica. Praag, 2018 nr. 4. pp. 131 - 138. 
die de opdracht hebben gekregen om twee keer naar een aantal korte zinnen te luisteren en de ontbrekende woorden aan te vullen. De zinnen waren afkomstig uit de leergang Nu versta $i k j e$ ! van Blomme et al. (2009), van een uitspraakleergang, de versie die ik in de opnamen liet horen was de Nederlands-Nederlandse uitspraak. In de acht zinnen kwamen bijvoorbeeld bekende uitdrukkingen aan bod zoals Wat is er aan de hand? of Had jij je er zo op verheugd? die de studenten vrijwel vlekkeloos konden begrijpen. De knelpunten bleken echter twee zinnen te zijn:

a) Ik heb er niet zo over nagedacht ${ }^{2}$ - en tot slot:

b) Hij kwam in geuren en kleuren vertellen wat ze gedaan hadden.

Bij 15 van de 17 studenten kwamen er in de eerste zin foutieve resultaten. Slechts twee antwoorden waren goed. Hieronder (zie Tabel 1) som ik de resultaten op, vetgedrukt staan de uitdrukkingen die mijn aandacht trokken:

Tabel 1: Opsomming van de realisaties van de zin: Ik heb er niet zo over nagedacht

\begin{tabular}{|c|c|}
\hline 1. $\mathrm{lk}$ heb het runds & \multirow[t]{9}{*}{ over nagedacht en ik doe het. } \\
\hline 2. Ik heb er zo'n & \\
\hline 3. Ik heb iets & \\
\hline 4. Ik heb er eens & \\
\hline 5. Ik hebben zo & \\
\hline 6. Ik heb zo van & \\
\hline 7. Ik heb het & \\
\hline 8. Ik heb zo & \\
\hline 9. Ik heb je & \\
\hline
\end{tabular}

Bij de eerste voorbeeldzin die met veel reductie werd uitgesproken, kunnen we zien dat de studenten de woorden $e$, niet en soms zo helemaal niet hebben kunnen verstaan of zoals in het derde voorbeeld het geval is, alleen een kenmerk van de allofoon hebben kunnen verstaan, namelijk dat het om een hoge voorklinker ging. In het vijfde voorbeeld heeft de student dan de centrale klinker in het woord $e r$ kennelijk wel gehoord maar als een werkwoordsuffix geïnterpreteerd.

Bij de tweede voorbeeldzin heb ik 10 fouten geregistreerd, maar in deze bijdrage ga ik er niet dieper op in. Samenvattend gezegd hebben de studenten een probleem gehad met de uitdrukking in geuren en kleuren waarin ze receptief niet vertrouwd leken met de realisatie van het -en op het woordeinde als een sjwa.

De bovenstaande voorbeeldzinnen waren een inspiratie voor mijn onderzoek naar de gereduceerde vormen in het Nederlands en in het Tsjechisch. Ik vroeg me af wat de reductie in de gesproken taal namelijk allemaal inhoudt. Verder welke soorten reductie het meest problematisch zijn en op welk niveau de NVT-studenten in staat zijn om de gereduceerde uitingen juist te ontcijferen? Ik vraag me af hoe er met de reducties wordt

2 cursief staat het deel dat ze moesten invullen 
omgegaan in de leerboeken NVT en in de uitspraakleergangen. En tot slot hoe we als taaldocenten met de reducties zouden moeten/zouden kunnen omgaan?

In deze bijdrage probeer ik op sommige van de vragen een antwoord te formuleren, sommige blijven nog onbeantwoord. Ook wil ik een schets geven van een pilotonderzoek naar de reductie en het begrip ervan dat ik verder dieper wil uitwerken.

\section{Reductie in het Nederlands en in het Tsjechisch}

In de laatste jaren krijgt het thema van reductieprocessen in de gesproken taal veel aandacht. In Nederland richt vooral Mirjam Ernestus zich in haar onderzoek op het thema van gereduceerde varianten in informele taal (verg. Ernestus - Warner 2011, Ernestus - Giezenaar 2014, Ernestus e. a. 2016). De reductie komt namelijk voor in allebei de varianten - zowel in de formele taal, zij het wat minder, als in de informele taal. Het onderzoek werd tot nu toe vooral gericht op dit fenomeen in het Nederlands Nederlands. Gereduceerde varianten komen in verschillende vormen naar voren. Er wordt over regelmatige en onregelmatige reductiepatronen gesproken (Ernsestus e. a. 2016: 7). Regelmatige reductiepatronen zijn goed te voorspellen, hierbij horen bijvoorbeeld het wegvallen van de klinkers in een onbeklemtoonde syllabe zoals in opera, gelijk enz., verder het wegvallen van de / $\mathrm{r} /$ na sjwa in woorden als verkopen, Haarlem, het wegvallen van de / $t$ / voor of na een medeklinker in woorden als Utrecht, orkest en het wegvallen van de nasalen voor de medeklinker zoals in vakantie, bandiet. (Ernestus e. a. 2016: 7) We kunnen eraan nog toevoegen dat de -en op het woordeinde ook regelmatig wegvalt. Het fenomeen van de reducties op het woordeinde en in de onbeklemtoonde syllabes is bij de NVT-leerders van het Nederlands vrij bekend. Volgens Ernestus e. a. (2016: 7-9) vallen dus in de bovengenoemde gevallen de vetgedrukte klanken regelmatig weg. Daarnaast zijn er volgens haar gevallen van onregelmatige oftewel extreme reductie waarin het oorspronkelijke woord grotendeels van vorm verandert. Een typisch voorbeeld zijn de woorden natuurlijk of gewoon waarvan tuuk, goon of zelfs minder klanken overblijven.

Zoals reeds gezegd, deze reductie is vooral kenmerkend voor de informele taal. Uit het onderzoek is verder gebleken dat sommige reducties wel voorspelbaar zijn, sommige niet. Ernestus en andere onderzoekers (verg. Ernestus - Warner 2011, Ernestus - Giezenaar 2014, Ernestus e. a. 2016) spreken vooral over frequente woorden en woordcombinaties die de eerste kandidaat zijn om gereduceerd te worden. (Ernestus e. a. 2016: 8) Het hoeft niet alleen om functiewoorden te gaan zoals in mijn eerste voorbeeldzin maar het kan ook om inhoudswoorden gaan van het type natuurlijk, gewoon, politici, Nederland, Nederlandse politici enz. Interessant is ook het aspect dat de gereduceerde varianten vaak in de spraak voorkomen van de ouder tegen het kind. (Ernsestus - Giezenaar 2014: 82) Dat betekent dus dat de Nederlandse moedertaalsprekers de gereduceerde uitspraakvarianten "met de paplepel ingegoten krijgen” aldus Ernestus. (Ernestus - Giezenaar 2014: 83).

Voor de NVT-studenten blijven de reducties echter wel een probleem. Naast het worstelen met de vreemde klanken, moeten ze nog aandacht besteden aan wat er in de taal ontbreekt. 
Wat de reductiepatronen in het Tsjechisch betreft, werd er in de canonieke Tsjechische fonetische en fonologische vakliteratuur tot voor kort voortdurend beweerd dat het Tsjechisch een taal is waarin reductie alleen een voorbeeld is van een slordige uitspraak en dat die dus in de formele taal niet is toegestaan. (verg. Krčmová 2008: 200-209, Palková 2004: 170-171) Als zodanig werd de reductie tot voor kort ook min of meer buiten beschouwing gelaten vooral omdat het slechts Standaardtsjechisch was, de norm, die onderzocht werd. In de laatste jaren richt het onderzoek zich toch ook op het informeel gesproken taal.

Terminologisch wordt er enerzijds over de klankreductie gesproken waarbij men kijkt of het om een verzwakte articulatie gaat of om de omissie van een segment of om de parallele articulatie wat betekent dat er slechts enkele kenmerken van de klank worden gehandhaafd. De klank kan dan slechts de zgn. minimale fonetische informatie blijven dragen, en dat betekent dat bijvoorbeeld bij de $/ \mathrm{n} /$ alleen de nasaliteit wordt gehandhaafd. (Machač 2013: 18-19) Zo heeft de spreker in onze eerste voorbeeldzin kunnen verstaan dat er in $i k$ hebben zo een centrale karakter van de klinker aanwezig was.

Net als in het Nederlands is het ook in het Tsjechisch het geval dat er in snelle spraak op het woordniveau klanken worden gereduceerd op zo'n manier die in het Nederlands als extreme reductie wordt aangeduid. Voorbeeld: samozřejmě kan in het extreme geval als sařejně (natuurlijk) worden uitgesproken. (Machač 2013: 19) Ook in het Tsjechisch geldt namelijk dat de functiewoorden eerder de neiging hebben om gereduceerd te worden. Een typisch voorbeeld is het voegwoord protože (daarom) dat veelal als bře wordt uitgesproken.Wat de vocalen zelf betreft, zijn er twee tendensen in het Tsjechisch te vinden. Ten eerste kunnen de vocalen min of meer tot een sjwa-achtige klank worden gereduceerd en ten tweede in de richting van de hoge vocalen / i/ en /u/. (Machač 2013: 19)

Over het Tsjechisch wordt verder beweerd dat de reducties veelal door de hypoarticulatie ontstaan dus door de articulatorische luiheid en dat ze dan in de taalstructuur verankerd worden. Het Nederlands is in deze context een taal met een niet vaste woordklemtoon en de beklemtoonde en onbeklemtoonde syllabes wisselen elkaar af. Het Tsjechisch heeft daarentegen een vaste woordklemtoon op de eerste syllabe, de nevenklemtoon komt in samenstellingen voor en laat de woordgrenzen zien. (Krčmová 2008: 171-172).

In de gesproken communicatie gaat het erom dat er over een thema wordt gesproken dat bekend is aan de spreker en de luisteraar. De context laat het dus toe dat er articulatorisch wat losser wordt gesproken waarbij dan vooral de frequente woorden en functiewoorden gereduceerd worden.

De mate en wijze van de reducties worden dan door de fonotactische regels van de taal bepaald. Voor een verder onderzoek is dit de eerste bouwsteen die moet worden gedefinieerd, namelijk welke fonotactische regels er zijn in het Nederlands en in het Tsjechisch om de tendensen van de reductieprocessen te kunnen omschrijven en om vast te kunnen stellen welke "foneemkenmerken" genoeg zijn om een gereduceerde taaluiting te kunnen verstaan. 


\section{Reductie in de recente leergangen onder de loep}

Gereduceerde vormen vormen dus knelpunten voor de NVT-leerders. De vraag is dan: in welke mate en hoe komen ze in aanraking met deze vormen?

We kunnen ten eerste naar twee uitspraakleergangen kijken die vrij recent zijn. In $\mathrm{Nu}$ versta ik je (Van Sleeuwen en Spaan 2013) (Nederlands-Nederlandse versie) wordt er expliciet niet op de gereduceerde uitspraakvarianten ingegaan. Wel komen ze in beperkte mate aan bod in de opnames. Er komen dan regelmatige reducties voor (op het woordeinde, in onbeklemtoonde syllabes). In de taalriedels komen de reducties lichtjes meer aan bod maar ook nog binnen de perken. Deze leergang heeft echter vooral als doel om de afzonderlijke klanken goed te laten inoefenen en een ander niveau dan het segmentele komt er eigenlijk niet aan bod.

Aan de andere kant hebben we de Uitspraaktrainer in de les. Uitspraakverbetering voor anderstaligen (Van Veen 2009) dat een handig en complex leerboek is waarin zowel theoretisch als praktisch ingegaan wordt op de fonetiek boven het segmentele niveau. Hoofdstuk 4 van dit boek richt zich op de verbonden spraak waarin ingegaan wordt op de zgn. zwakke vormen, weglating van klanken, verbinding van klanken en andere knelpunten voor de NVT-leerders. NVT-leerders kunnen dus receptief én productief bijvoorbeeld de gevallen van verzwakte functiewoorden (lidwoorden, persoonlijke voornaamwoorden, het woordje er enz.) leren en daardoor worden ze op de echte gesproken taal voorbereid.

Naast de uitspraakleergangen heb ik naar de leergang Contact 1, 2, 3 (De Leeuw et al. 2014, 2015a, 2015b) gegeken en ik kan constateren dat er veelal natuurlijke gesprekken in voorkomen waar dus ook veel gereduceerde uitspraakvormen zijn. Ik kan eraan toeveogen dat de studenten soms klagen dat ze de gesprekken moeilijk verstaan vooral omwille van het spreektempo én de reducties.

\section{Pilotonderzoek}

Het pilotonderzoek naar het verstaan van gereduceerde vormen door Tsjechische studenten Nederlands bestond uit twee delen. Ten eerste moesten de studenten naar drie dialogen - afkomstig uit het boek Contact 3 (De Leeuw et al. 2015b) - luisteren. Ik heb met opzet een leergang gebruikt waarmee de studenten nog niet hebben gewerkt. De taak was om twee keer te luisteren, één keer in zijn geheel, de tweede keer in stukjes en ze moesten woorden en zinnen invullen die ontbraken. In de fragmenten waren sprekers die veel reducties gebruikten, sprekers die vrij duidelijk en ongereduceerd spraken en één spreker die slordig of bijna dialectisch sprak. Deze opnames werden in de pilotstudie aan studenten van niveau A2+/B1 voorgelegd, namelijk tweedejaars op het einde van hun tweede jaar. Uiteindelijk heb 4 antwoorden van de deelnemers gekregen.

Het tweede deel was een vragenlijst waarin ze de opnames op verstaanbaarheid moesten beoordelen en ook vragen moesten beantwoorden omtrent de knelpunten van verstaanbaarheid van het Nederlands. Ook werden ze gevraagd naar het Tsjechisch en hun ervaring met het wergslikken van de klanken in deze taal. 
De opnames waren drie korte fragmenten waarin telkens twee mensen met elkaar een dialoog voerden. In de eerste situatie was het een gesprek van een verslaggever en een politicus waarin allebei tamelijk snel spraken. De tweede dialoog verliep tussen een dokter en een patiënt, waarin de dokter langzaam en heel duidelijk sprak en de patiënt wat sneller en gebruik maakte van reducties. Het derde dialoog was tussen een politieagent en een verdachte die een slordige en wat gekleurde uitspraak had.

In de gatentekst wilde ik vooral de volgende aspecten van de waarneming van reductie onderzoeken.

1. Hoe goed verstaan de studenten de snelle spraak waar reducties in voorkomen?

2. Hoe goed begrijpen ze onbekende gereduceerde inhoudswoorden zowel bekende als onbekende van het type verkeer, loodsen, aan zet (zijn)?3

3. Hoe goed verstaan ze functiewoorden, met name lidwoorden, partikels, verwijswoorden, voornaamwoorden zoals vertel het eens, laten we maar eens kijken, ik mag toch wel ergens rondlopen, is dat zo?

4. Hoe goed verstaan ze sterk gereduceerde vormen waarin alleen minimale fonetische informatie in voorkomt zoals $i k$ heb zo'n last van.

5. Hoe goed verstaan ze collocaties van het type in beslag nemen?

\subsection{Resultaten van de luisteroefeningen / het eerste deel pilotonderzoek}

In de volgende tabellen wil ik de meest problematische punten samenvatten die de verstaanbaarheid in de weg stonden.

Tabel 2: Begrip van bekende en onbekende gereduceerde woorden

\begin{tabular}{|l|l|l|}
\hline Getoetste uitdrukkingen & $\begin{array}{l}\text { percentages } \\
\text { correcte } \\
\text { zinnen }\end{array}$ & Eventuele voorbeeldfouten \\
\hline verkeer & $100 \%$ & notje \\
\hline door het parlement loodsen & $0 \%$ & alleen het bekende woord eerst was opgeschreven \\
\hline $\begin{array}{l}\text { het parlement is nu eerst } \\
\text { aan zet }\end{array}$ & $50 \%$ & \\
\hline
\end{tabular}

Samenvatting van de meest problematische voorbeelden:

In het luisterfragment werden de zinnen snel uitgesproken en het grootste knelpunt waren de inhoudswoorden en uitdrukkingen die op het niveau van A2 vrijwel onbekend waren.

3 Bij onbekende woorden van het type loodsen, aan zet zijn wilde ik namelijk toetsen of ze die überhaput konden begrijpen. In een verder onderzoek zou ik ook willen nagaan of zo' $n$ woord de verstaanbaarheid van de hele zin belemmert of of de studenten minstens kunnen ontcijferen of het om een werkwoord of een zelfstandig naamwoord gaat enz. 
Effe nog eens zeggen. De weggelaten klanken in het Nederlands - de afgebroken bruggen ...

Tabel 3: Begrip van collocaties

\begin{tabular}{|l|l|l|}
\hline Getoetste uitdrukkingen & $\begin{array}{l}\text { percentages } \\
\text { correcte zinnen }\end{array}$ & Eventuele voorbeeldfouten \\
\hline nog in beslag nemen & $25 \%$ & \\
\hline
\end{tabular}

In tabel 3 geef ik als voorbeeld een uitdrukking die wel bekend was bij de deelnemers aan het onderzoek maar het voorzetsel werd in deze uitdrukking wel misgeïnterpreteerd als onbepaald lidwoord in de snel uitgesproken zin.

Tabel 4: Begrip van functiewoorden

\begin{tabular}{|c|c|c|}
\hline Getoetste uitdrukkingen & $\begin{array}{l}\text { percentages } \\
\text { correcte zinnen }\end{array}$ & Eventuele voorbeeldfouten \\
\hline eerst maar eens goedkeuren & $0 \%$ & nog eens \\
\hline vertel het eens, wat is er aan de hand & $100 \%$ & \\
\hline Nou, laten we maar eens kijken & $0 \%$ & $\begin{array}{l}\text { we eens } \\
\text { we nog eens } \\
\text { eens } \\
\text { we ons }\end{array}$ \\
\hline Oh, is het zo? & $0 \%$ & oh, is dat zo \\
\hline $\begin{array}{l}\text { Oh, ik kan me het namelijk niet herin- } \\
\text { neren. }\end{array}$ & $50 \%$ & $\begin{array}{l}\text { Ik me nou niet herinneren } \\
\text { Ik kan het me aan niet herinneren } \\
\text { ik kan me namelijk moeten herinneren }\end{array}$ \\
\hline
\end{tabular}

Tabel 4 bevat de getoetste functiewoorden en men kan vaststellen dat de functiewoorden inderdaad het grootste knelpunt waren voor de NVT-studenten van het Nederlands. Er kan worden vastgesteld dat vooral de partikels en een reeks functiewoorden achter elkaar moeilijk zijn voor het begrip op het A2-niveau.

Tabel 5: Extreme reductiegevallen

\begin{tabular}{|l|l|l|}
\hline nou, ik heb zo' $n$ last van mijn rug & $50 \%$ & ik heb zo last van \\
\hline $\begin{array}{l}\text { lk zeg niet dat ik er was, maar ik mag toch } \\
\text { wel ergens rondlopen. }\end{array}$ & $0 \%$ & $\begin{array}{l}\text { Ik zei niet dat ik er was, - } \\
\text { lk zei dat, (maar ik mag) rondlopen }\end{array}$ \\
\hline
\end{tabular}

In tabel 5 staan voorbeelden van gevallen waarin extreme reductie voorkwam. Beide gevallen waren in de opnames zeer snel uitgesproken en zorgden voor veel moeilijkheden bij de deelnemers aan het onderzoek.

\subsection{Resultaten van de vragenlijst}

In de vragenlijst gaven de respondenten aan dat de twee moeilijkst verstaanbare sprekers spreker B van het eerste gesprek (de politicus) en spreker B van de laatste opdracht (de verdachte) waren. De grootste problemen werden veroorzaakt door de onduidelijke 
uitspraak en het wegslikken van sommige woorden en daarna de snelheid van de spraak. Tevens gaven studenten aan dat ze de grootste moeite hadden met het begrijpen van het Nederlands Nederlands voor ze dus de gereduceerde uitspraak als zodanig vormt die soms het begrip van de hele zin of het fragment in de weg staat.

Over het Tsjechisch denken ze daarentegen dat de uitspraak van het Tsjechisch helder is en dat er heel weinig tot nul reductie in voorkomt.

\section{Conclusie}

Uit het pilotonderzoek blijkt dat de gereduceerde uitspraak zeker nog op het niveau $\mathrm{A} 2+/ \mathrm{B} 1$ en later de verstaanbaarheid in de weg staat. Contrastief gezien zie ik bij de Tsjechische studenten drie aspecten waarop men zich in de uitspraakles kan concentreren. Ten eerste moet er aandacht worden besteed aan de prosodie en aan het receptief en productief oefenen van de woord- en zinsklemtoon en de zinsmelodie. Ten tweede op het inoefenen van regelmatige reductiepatronen, zinnen die veel functiewoorden - vooral partikels bevatten en ten derde op het doelgericht luisteren naar authentiek materiaal waarin de gereduceerde varianten voorkomen die ten dele veroorzaakt zijn door de ritmische structuur van het Nederlands die zoveel van de Tsjechische verschilt.

Dit pilotonderzoek neem ik als een uitgangspunt voor een grootschaliger onderzoek naar de verstaanbaarheid van de reductieprocessen dat ik bij de niveaus A2, B2 en C1 wil uitvoeren om uit te testen hoe de verstaanbaarheid zich ontwikkelt en wat de struikelblokken blijven.

Soms zullen we dus enkele zinnen effe nog eens moeten zeggen om de afgebroken brug van de verstaanbaarheid weer te kunnen repareren.

\section{Literatuurlijst}

Beheydt, Ludo (2010): "Culturele identiteit en normativiteit", in: Liever meer of juist minder? Over normen en variatie in taal. Gent: Academia Press, p. 1-14.

de Leeuw, Elsbeth, et al. (2014): Contact 1! Nederlands voor anderstaligen. Tekstboek. Amsterdam/ Antwerpen: Intertaal.

de Leeuw, Elsbeth, et al. (2015a): Contact 2! Nederlands voor anderstaligen. Tekstboek. Amsterdam/ Antwerpen: Intertaal.

de Leeuw, Elsbeth, et al. (2015b): Contact 3! Nederlands voor anderstaligen. Tekstboek. Amsterdam/ Antwerpen: Intertaal.

Ernestus, Mirjam \& Ghislaine Giezenaar \& Mirte Dikmans (2016): Ikfstajezotuuknie: Half uitgesproken woorden in alledaagse gesprekken. Les 199, p. 7-9

Ernestus, Mirjam \& Natasha Warner (2011): "An Introduction to Reduced Pronunciation Variants" In: Journal of Phonetics 39, p. 253-260.

Ernestus, Mirjam \& Ghislaine Giezenaar (2014): "Een goed verstaander heeft maar een half woord nodig” In: B. Bossers (ed.), Vakwerk 9, Achtergronden van de NT2-lespraktijk. Lezingen conferentie Hoeven 2014, Amsterdam: Boom. p. 81-92. 
ERK- Gemeenschappelijk Europees Referentiekader voor Moderne Vreemde Talen: Leren, Onderwijzen, Beoordelen. URL: http://taalunieversum.org/sites/tuv/files/downloads/gemeenschappelijk_europees_referentiekader.pdf. Geraadpleegd 15 maart 2021.

Krčmová, Marie (2008): Úvod do fonetiky a fonologie pro bohemisty. Ostrava: Ostravská univerzita v Ostravě.

Machač, Pavel (2013): K české fonetice a pravopisu. Olomouc: Univerzita Palackého v Olomouci.

Palková, Zdena (1997): Fonetika a fonologie češtiny s obecným úvodem do problematiky oboru. Praha: Univerzita Karlova, Karolinum.

van Sleeuwen, Gabri en Anneloes SPAAN (2013): Nu versta ik je! Uitspraak Nederlands voor anderstaligen. Leuven/Den Haag: Acco.

van Veen, Chris (2009): Uitspraaktrainer in de les. Uitspraakverbetering voor anderstaligen. Amsterdam: Boom.

Mgr. Marta Kostelecká, Ph.D. / marta.kostelecka@gmail.com

Masarykova univerzita, Filozofická fakulta, Ústav germanistiky, nordistiky a nederlandistiky Arna Nováka 1, 60200 Brno, CZ 